\title{
An Assessment of Attitudes towards and Practices of Food Hygiene among Babcock University Cafeteria Workers
}

\author{
Article by Asekun-Olarinmoye IO*, Asekun-Olarinmoye EO**, Igbokwe C* \\ *Department of Public Health, School of Public and Allied Health, College of \\ Medicine, Babcock University, Ilishan-Remo, Ogun State, Nigeria \\ **Department of Community Medicine, College of Health Sciences, Faculty of \\ Clinical Sciences, Osun State University, Osogbo, Osun State, Nigeria \\ Email: ifeoluwapo.oyebola@gmail.com
}

\begin{abstract}
This descriptive cross-sectional study assessed various hygiene practices among 250 Babcock University cafeteria workers, and the hygienic condition of the working environment. Most of the respondents, 126 (50.4\%) were ever married, females 146 (58.4\%), Christians 208 (83.2\%) and of the Yoruba ethnic group, 128 (51.2\%). Result findings revealed that 226(90.4\%) respondents had good knowledge of food hygiene, and 206(82.4\%) knew that protective wears reduce the risk of food contamination and accidents in the cafeteria. However, 167(66.8\%) of the respondents were not aware that virus causes food contamination. Only 83(33.2\%) of the respondents indicated that they clean their working environment two times a day while 41(16.4\%) of the respondents clean once a day meaning majority of the respondents, 126 (51.4\%) do not clean regularly resulting in a questionable working environment. Findings also show that only 60 (24\%) respondents use personal protective equipment (PPE) any time they are in the cafeteria while 104 (41.6\%) make use of $P P E$ when preparing and serving food. Bi-variate (Chi-square test statistics) analysis revealed significant relationships between attitude and age $(p=0.05)$; hygiene level of working environment and tribe $(p=0.008)$; level of hygiene practices versus marital status $(p=0.035)$ and tribe $(p=0.001)$; level of use of PPE versus marital status $(p=0.006)$ and knowledge of respondents $(p=0.001)$. The study concluded that though workers in Babcock University cafeteria have satisfactory level of knowledge and good attitude towards food hygiene practices, their level of environmental hygiene practices are not adequate. Recommendations include training programs to re-orientate the workers on proper environmental hygiene practices and daily work environment inspections.
\end{abstract}

Keywords: Food, Hygiene, Safety, Cafeteria, Contamination,

\section{Introduction}

Studies have shown that kitchen staff and food handlers of a cafeteria are common sources of bacterial and viral contamination in foods (Gashaw et al 2008).

The food services department (cafeteria) is a vital unit in Babcock University. It provides the students with meals that are nutritiously balanced; aiming to reduce the intake of junk foods, and the risk of food-borne diseases. This study explored various hygiene practices among cafeteria workers, and assessed the hygienic condition of the working environment. It sought to assess the attitude and perception of the workers towards hygiene practices.

\section{Methodology}

This descriptive cross-sectional study was carried out in Babcock University using the University's cafeteria workforce. The study population consisted of two hundred and fifty people, all workers at the University cafeteria. Data was collected using a pre-tested selfadministered questionnaire. The questionnaire was made of four sections, consisting of respondents' demographic data, awareness and knowledge of food hygiene among respondents, the attitude/ perception of the respondents towards food hygiene, and the food 
hygiene practices of the respondents. A total sampling of the entire workforce at the cafeteria was done and informed consent was obtained from all respondents. Five students from the Department of Public Health, Babcock University were trained as research assistants who administered the questionnaires to the respondents. Data was pre-coded and entered into a computer using Statistical Package for Social Sciences (SPSS) Version 21. Measurement of outcome variables was computed by awarding one mark for each correct answer and no mark for incorrect answer. Eighteen (18) items were used to assess the respondents' level of knowledge on food hygiene, seven (7) items for respondents' attitudes towards food hygiene/safety and seven (7) items also for assessing respondents' level of hygiene practice while one item was chosen to assess the working environment's level of hygiene. Simple frequency tables were generated and Chi-square test statistics was used to demonstrate relationships between categorical variables at $95 \%$ confidence interval with level of significance set at $p$-values $\leq 0.05$ for all inferential analysis.

\section{Results}

Table 1: Socio-demographic Characteristics of Respondents $(n=250)$

\begin{tabular}{|l|l|}
\hline Socio-demographic Variable & Frequency (\%) \\
\hline Gender & $104(41.6)$ \\
Male & $146(58.4)$ \\
Female & \\
Age group & $31(12.4)$ \\
Below 20 & $198(79.2)$ \\
$21-40$ & $21(8.4)$ \\
40 and above & $124(49.6)$ \\
Marital status & $126(50.4)$ \\
Never Married & \\
Ever Married & $208(83.2)$ \\
Religion & $33(13.2)$ \\
Christian & $9(3.6)$ \\
Muslim & $81(32.4)$ \\
Others (e.g. Traditional, etc) \\
Tribe & $27(10.8)$ \\
Igbo & $128(51.2)$ \\
Hausa & $14(5.6)$ \\
Yoruba & \\
Others & $11(4.4)$ \\
Educational status & $90(36.0)$ \\
No Education & $149(59.6)$ \\
< Secondary Education & >Secondary Education
\end{tabular}

A total of 250 questionnaires were administered and all were retrieved, validated and analyzed, giving a response rate of $100.0 \%$. One hundred and four $(41.6 \%)$ of the respondents were males, $126(50.4 \%)$ were ever married, Christians 208 (83.2\%) and of the Yoruba ethnic group, $128(51.2 \%)$. Only $11(4.4 \%)$ of the respondents had no formal education with majority of the respondents, $149(59.6 \%)$ having greater than secondary education.

Table 2: Awareness and Knowledge of respondents about food hygiene $(n=250)$

\begin{tabular}{lll}
\hline Variables & Yes (\%) & No (\%) \\
Have you ever heard about food hygiene? & $226(90.4)$ & $24(9.6)$ \\
$\begin{array}{l}\text { Can food contamination result from improper food or } \\
\text { personal hygiene? }\end{array}$ & $228(91.2)$ & $22(8.8)$ \\
Does making use of a clean dish towel to wipe dishes after & $128(51.2)$ & $122(48.2)$
\end{tabular}


washing contribute to food contamination?

Do you think the use of protective wears in the cafeteria is $226(90.4) \quad 24$ (9.6) necessary?

Does the use of personal protective wears reduce the risk $206(82.4) \quad 44$ (17.6)

of food contamination and accidents in the cafeteria?

Do you think a food handler should have knowledge on 215 (86.0) 35 (14.0)

personal hygiene and food safety?

Is the risk of food getting contaminated, dependent on the $190(76.0) \quad 60(24.0)$

health status and personal hygiene of food handlers?

Are food handlers expected to prepare food or work when $\quad 76(30.4) \quad 174$ (69.6) ill?

This table shows a high level of awareness about food hygiene with majority of the respondents, 226 (90.4\%) answering 'yes' to the question "Have you ever heard about food hygiene?" while 206 (82.4\%) knew that protective wears reduce the risk of food contamination and accidents in the cafeteria. Furthermore, 190(76.0\%) of the respondents knew that the risk of food getting contaminated depends on the health status of food handlers. $174(69.6 \%)$ of the respondents also knew that food handlers should not work when ill.

Table 3: Respondents' response on the correct basic steps for hand washing $(\mathrm{n}=250)$

\begin{tabular}{lll}
\hline Variable & Options & Number \\
\hline $\begin{array}{l}\text { What are the basic steps for } \\
\text { washing hands? }\end{array}$ & Wash thoroughly with water and dry & $66(26.4 \%)$ \\
& $\begin{array}{l}\text { Apply soap, wash thoroughly, rinse and use } \\
\text { paper towels } \\
\text { Apply soap, wash thoroughly }\end{array}$ & $139(55.6 \%)$ \\
\hline
\end{tabular}

Table 3 shows that only 139 (55.6\%) of the respondents knew the correct basic steps for hand washing.

Table 4: Respondents' knowledge of causes and route of transmission of food contamination ( $\mathrm{n}=250)$

\begin{tabular}{lcc}
\hline Options & Yes (\%) & No (\%) \\
Which of the following agents cause & food contamination? \\
Virus & $83(33.2)$ & $167(66.8)$ \\
Bacteria & $222(88.8)$ & $28(11.2)$ \\
Fungi & $119(47.6)$ & $131(52.4)$ \\
Which of the following does bacteria & need to assist it to grow and multiply? \\
Water & $165(66.0)$ & $85(34.0)$ \\
Food & $183(73.2)$ & $67(26.8)$ \\
Warm temperatures & $83(33.2)$ & $167(66.8)$ \\
When can food be contaminated? & \\
During preparation & $215(83.0)$ & $35(14.0)$ \\
When being served & $127(50.8)$ & $123(49.3)$ \\
\hline
\end{tabular}

Majority of the respondents, $167(66.8 \%)$, did not know that food can be contaminated by viruses. It is interesting to note that more respondents, $215(83.0 \%)$ said that food can be contaminated during preparation than when being served.

Table 5: Respondents' food safety and hygiene practices $(\mathrm{n}=250)$

\begin{tabular}{|c|c|c|}
\hline Variables & Yes (\%) & No (\%) \\
\hline Do you talk when preparing food? & $108(43.2)$ & $142(56.8)$ \\
\hline $\begin{array}{l}\text { Do you use Personal Protective Equipment (PPE) all the time in } \\
\text { the workplace? }\end{array}$ & $60(24.0)$ & $190(76.0)$ \\
\hline Do you make use of PPE such as gloves? & $145(58.0)$ & $105(42.0)$ \\
\hline
\end{tabular}


South American Journal of Public Health

Special Edition May 2016

Do you make use of PPE such as Mouth and nose Cover?

$97(38.8)$

$153(61.2)$

Do you make use of PPE such as aprons?

$193(77.2) \quad 57(22.8)$

Do you make use of PPE such as hair covers?

$172(68.8) \quad 78(31.2)$

Do you wash your hands regularly?

$221(88.4) \quad 29(11.6)$

Table 5 shows that a significant number of respondents, 108(43.2\%), talk when preparing food, with majority of respondents, $153(61.2 \%)$, stating they do not use mouth covers and only $60(24.0 \%)$ respondents signified using PPE at all times in the cafeteria. Two hundred and twenty-one respondents, 221(88.4\%), indicated regular hand washing.

Table 6: Respondents' attitudes towards food hygiene and safety measures $(n=250)$

\begin{tabular}{|c|c|c|}
\hline Variable & Agree (\%) & Disagree (\%) \\
\hline $\begin{array}{l}\text { Washing of hand before handling of food in the kitchen is a } \\
\text { good measure of food safety and hygiene }\end{array}$ & $250(100.0)$ & $0(0.0)$ \\
\hline $\begin{array}{l}\text { Proper washing of hands after using the toilet as a food } \\
\text { handler can prevent contamination of food }\end{array}$ & $240(96.0)$ & $10(4.0)$ \\
\hline $\begin{array}{l}\text { Covering of hair while preparing food is a good measure to } \\
\text { prevent contamination of food }\end{array}$ & $242(96.8)$ & $8(3.2)$ \\
\hline Clean environment prevents contamination of food & $239(95.6)$ & $11(4.4)$ \\
\hline $\begin{array}{l}\text { Covering of cuts immediately after any form of accident in } \\
\text { the kitchen by the food handlers promotes food safety and } \\
\text { hygiene }\end{array}$ & $214(85.6)$ & $6(14.4)$ \\
\hline Use of hand sanitizers is not part of food hygiene practice & $105(42.0)$ & $145(58.0)$ \\
\hline $\begin{array}{l}\text { Refrigeration of food is not a good measure to prevent food } \\
\text { contamination }\end{array}$ & $87(34.8)$ & $163(65.2)$ \\
\hline
\end{tabular}

The table 6 shows that all respondents, 250 (100.0\%), agreed that washing of hands before handling food in the kitchen is a good measure of food safety and hygiene but majority of the respondents, $145(58.0 \%)$, disagreed with the use of hand sanitizers as part of food hygiene practice.

Table 7: Respondents' response on how often their working environment is cleaned $(\mathrm{n}=250)$

\begin{tabular}{|l|l|l|}
\hline Variable & Option & Number \\
\hline $\begin{array}{l}\text { How often do you clean the } \\
\text { working environment? }\end{array}$ & Twice a day & $83(33.2 \%)$ \\
\hline & Once a day & $41(16.4 \%)$ \\
\hline & More than twice a day & $87(34.8 \%)$ \\
\hline & More than twice a week & $31(12.4 \%)$ \\
\hline & More than twice a week but not everyday & $8(3.2 \%)$ \\
\hline
\end{tabular}

Table 7 shows frequency of cleaning work environment among respondents. Eighty-three $(33.2 \%)$ of the respondents indicated that they clean their working environment two times a day while $41(16.4 \%)$ of the respondents clean once a day meaning majority of the respondents, 126 (51.4\%) do not clean regularly (at least once a day).

Table 8: Knowledge, Attitude and Hygiene Practice categories among Respondents

\begin{tabular}{llc}
\hline Variable Scores & \multicolumn{2}{c}{ Categories } \\
\cline { 2 - 3 } & \multicolumn{1}{c}{ Poor $(\%)$} & \multicolumn{1}{c}{ Good (\%) } \\
\hline Knowledge & $27(10.8)$ & $223(89.2)$ \\
Attitude & $8(3.2)$ & $242(96.8)$ \\
Hygiene Practice & $81(32.4)$ & $169(67.6)$ \\
Working Environment Hygiene Practice & $167(66.8)$ & $83(33.2)$ \\
\hline
\end{tabular}


The composite table above shows Knowledge, attitude, practice and environment hygiene categories of the study respondents. Majority $(89.2 \%)$ of respondents had good knowledge, positive attitudes $(96.8 \%)$, good hygiene practices $(67.6 \%)$ but poor working environment hygiene practice $(33.2 \%)$.

Table 9: Association between socio-demographic variables and study objectives

\begin{tabular}{|c|c|c|c|c|c|}
\hline \multirow[t]{2}{*}{ Variable } & & \multicolumn{2}{|l|}{ Attitude } & \multirow[t]{2}{*}{ p-value } & \multirow[t]{2}{*}{ Remark } \\
\hline & & $\begin{array}{l}\text { Negative } \\
(\%)\end{array}$ & Positive (\%) & & \\
\hline \multirow[t]{4}{*}{ Age } & 30 and below & $8(4.6)$ & $165(95.4)$ & $0.05^{*}$ & Significant \\
\hline & 31 and above & $0(0.0)$ & $77(100.0)$ & & \\
\hline & & \multicolumn{2}{|c|}{$\begin{array}{l}\text { Hygiene level of working } \\
\text { environment }\end{array}$} & & \\
\hline & & Poor (\%) & Good (\%) & & \\
\hline \multirow{4}{*}{ Tribe } & Non-Yoruba & $109(89.3)$ & $13(10.7)$ & .008 & Significant \\
\hline & Yoruba & $99(77.3)$ & $29(22.7)$ & & \\
\hline & & \multicolumn{2}{|c|}{$\begin{array}{l}\text { Level of respondent } \\
\text { Hygiene Practices }\end{array}$} & & \\
\hline & & Poor (\%) & Good (\%) & & \\
\hline \multirow[t]{2}{*}{ Tribe } & Non-Yoruba & $53(43.4)$ & $69(56.6)$ & .000 & Significant \\
\hline & Yoruba & $28(29.9)$ & $100(78.1)$ & & \\
\hline \multirow[t]{4}{*}{ Marital status } & Never married & $33(26.6)$ & $91(73.4)$ & .035 & Significant \\
\hline & Ever married & $48(38.1)$ & 78 (61.9) & & \\
\hline & & \multicolumn{2}{|c|}{$\begin{array}{l}\text { Level of Personal protective } \\
\text { Equipment Use }\end{array}$} & & \\
\hline & & Poor (\%) & Good (\%) & & \\
\hline \multirow{2}{*}{ Marital Status } & Never married & $49(39.5)$ & $75(60.5)$ & .006 & Significant \\
\hline & Ever married & $71(56.3)$ & $55(46.7)$ & & \\
\hline \multirow[t]{2}{*}{ Knowledge } & Poor & $19(15.8)$ & $8(6.2)$ & .001 & Significant \\
\hline & Good & $101(84.2)$ & $122(93.8)$ & & \\
\hline
\end{tabular}

*Fisher's Exact Test Value used

Bivariate analysis revealed significant relationships between Attitude and Age $(p=0.05)$, hygiene level of working environment and tribe $(\mathrm{p}=0.008)$, level of hygiene practices versus marital status $(\mathrm{p}=0.035)$ and tribe $(\mathrm{p}=0.000)$; level of use of PPE versus marital status $(\mathrm{p}=0.006)$ and knowledge of respondents $(\mathrm{p}=0.001)$.

\section{Discussion}

This study showed that workers in Babcock University cafeteria have adequate knowledge on food hygiene; this may be due to the high educational status in the majority. Studies by Muinde \& Kuria (2005) revealed that food handlers often have poor level education, are unlicensed, untrained in food hygiene, technology and work under crude unsanitary conditions. However, Siow (2011) carried out a study in two university cafeterias, and found out that the knowledge of the workers were moderate. A study carried out by Unusan (2007) showed that food safety attitudes and knowledge of a person differ significantly on the basis of his/her educational status. Lin and Sneed (2005) found that enhancing knowledge can change behaviours and practices. This study also found that $76(30.4 \%)$ of the respondents felt 
that food handlers can be allowed to work even when ill. However, the research of Bryan (1998) had established that food handlers who are symptomatically ill may present a real hazard and should be excluded from work.

This study revealed that workers in Babcock university cafeteria have positive attitude towards food hygiene. In contrast though, Bas et al. (2004) in his series found that the attitude scores of the food handlers toward food borne diseases prevention and control was poor, and stated that attitude is an important factor that ensures a reduction trend of food borne diseases. Findings from this study also corroborate the fact that $t$ attitude is an important factor.

The study revealed that workers in Babcock university cafeteria have good level of hygiene practice. This may be due to their high knowledge on food hygiene, since studies have shown that knowledge influences behaviour and practice. Bryan (1988) stated that when food handlers do not practice good personnel hygiene or proper handling, they can be the vector for growth of microorganisms through hands, cuts, mouths, skins and hairs. A study by Green, Selman, Banerjee, Medus, Angulo and Buchanan (2005) showed that 25\% of food service workers do not always wash their hands, and $22 \%$ of them do not change gloves between touching raw meat or poultry and ready to eat food. On the contrary a moderately high proportion of respondents in this study practice washing of hands

The use of personal protective wears by workers in Babcock University cafeteria is on a moderate level. A low percent of the workers (24\%) use personal protective equipment PPE) always whenever they are in the cafeteria while a slightly higher percent $(41.6 \%)$ use PPE only when preparing and serving food. According to Newport (2010), food handlers have a moral and a legal responsibility to ensure that bacteria and other contaminants are not introduced into food. Hence, uniform must be worn at all times when on duty. All food service and food handling personnel should be aware that a high standard of personal hygiene such as effective hand washing and use of gloves is of paramount importance in terms of preventing food contamination and further in preventing the spread of infectious diseases (Angelillo et al., 2001).

It is interesting to note that even though respondents have good knowledge and attitude, study findings revealed that the hygienic condition of Babcock university cafeteria work environment is low. A similar finding was reported by Jay et al (1999) from their study in Australia where despite the high level of knowledge and attitude most of the workers, food handlers were reported to apply poor working techniques and to pay only casual attention to cleanness. Another study found that kitchen staff developed positive attitudes towards food safety but that they made mistakes in the working environment hygiene (Angelillo et al., 2001).

\section{Conclusion}

This study concludes that though workers in Babcock University cafeteria have satisfactory knowledge on food hygiene, as well as good attitude towards food hygiene, the hygiene condition of the working environment is questionable. This may be as a result of knowledge not put into correct practice. Despite the knowledge and awareness of food handlers on food hygiene, proper attention is still not given to the working environment.

\section{Recommendations}

Training programs should be frequently organized by the management of Babcock University cafeteria, to re-orientate the workers on proper sanitation and proper food hygiene practices. Working environment/area inspections should also be conducted on daily basis, perhaps several times a day. Personal protective wears such as gloves, apron, nose/mouth cover, as well as foot wears should be made available to the workers, to prevent accidents and food contamination and workers should be mandated to make use of them always. Workers should pay attention to their working environment; by always keeping it clean at all times to prevent food contamination. Further study is intended to determine possible association between disease incidence in student population and the meals served by the cafeteria. This 
might further impress upon the management, the need to ensure that food hygiene practices are always high, properly and correctly observed by all cafeteria workers.

\section{References}

[1.] Abhay, B.M. (2010). Health Status and Personal Hygiene among Food Handlers Working at Food Establishment around a Rural Teaching Hospital in Wardha District of Maharashtra, India. Global Journal of Health Science; 2(2): 190-206

[2.] Aimee, S., Pragle, M.S., Anna, K., James, C. (2007). Food Workers' Perspectives on Handwashing Behaviors and Barriers in the Restaurant Environment. Journal of Environmental Health Volume; 69(10): 27-32

[3.] Angelillo, F., Viggiani, N. M. A., Greco, R. M., \& Rito, D. (2001). HACCP and food hygiene in hospital: knowledge, attitudes, and practices of food-services staff in Calabria, Italy. Infection Control and Hospital Epidemiology, 22(6):1-7

[4.] Barro, N., Bello, A.R., Itsiembou, Y., Savadogo, A., Ouattara, C.A., Nikiema, A.P (2007). StreetVended Foods Improvement: Contamination Mechanisms and Application of Food Safety Objective Strategy: Critical Review. Pakistan Journal of Nutrition; 6 (1): 1-10.

[5.] Ehizibolo, D.O., Chukwu, C.O., Chukwu, I.D., Muhammad, M.J., and Olabode, A.O. (2007). Occurrence of Food borne Bacteria Pathogen in Smoked fish at Retail Level in Jos, Nigeria. Nigerian Veterinary Journal; 28(1):21-26.

[6.] Gashaw I, Stiller S, Boing C, Kimmig R, Winterhager E. Premenstrual regulation of the proangiogenic factor CYR61 in human endometrium. Endocrinology. 2008:149:2261-2269

[7.] Green, L.R., C.A. Selman, V. Radke, D. Ripley, J.C. Mack, D.W. Reimann, T. Stigger, M. Mostinger, and L. Bushnell. 2006. Food worker hand washing practices: an EHS-Net observation study. Journal of Food Protection. 69(10):2417-23

[8.] Ifenkwe, G.E. (2012). Food safety regulations: reducing the risk of food-borne diseases in rural communities of Abia state, Nigeria. Agricultural Science Research Journals; 2(7): 384-389.

[9.] Maizun, M.Z., Nyi, N.N. (2002). Sociodemographic Characteristics of Food Handlers and Their Knowledge, Attitude and Practice towards Food Sanitation: A Preliminary Report. Southeast Asian J Trop Med Public Health; 33(2):410-417

[10.] Mulugeta, K and Bayeh, A. (2012). The Sanitary Conditions of Food Service Establishments and Food Safety Knowledge and Practices of Food Handlers in Bahir Dar Town. Ethiopian Journal of Health Science; 22(1): 27-35.

[11.] Murat, B., Azmi, S.E., Gokhan, K. (2006). The Evaluation of Food Hygiene Knowledge, Attitude and Practices of Food Handlers in Food Businesses in Turkey. Journal of food control; 17: 317-322.

[12.] Nevin, S., Faith, T. (2010). Perceptions of Hygiene among Staff Working in Food Companies. Research Journal of Medical Sciences;4(3):231-237.

[13.] Oranusi, S., Galadima, M., Umoh, V.J. and Nwanze, P.I. (2007). Food safety evaluation in boarding schools in Zaria, Nigeria, using the HACCP system Scientific Research and Essay; 2(10): 426-433.

[14.] Orefi, A. (2012) Food Security in Nigeria and South Africa: Policies and Challenges. J Hum Ecol, 38(1): 31-35.

[15.] Siow, O., Norrakiah, A.S. (2011). Assessment of Knowledge, Attitudes and Practices (KAP) Among Food Handlers at Residential Colleges and Canteen Regarding Food Safety. Sains Malaysian; 40(4):403-410.

[16.] William, G.K., Bekker, J.L. and Onyango, R.O. (2012). An Assessment of Knowledge, Attitudes and Practices of Food Handlers in Food Kiosks In Relation To Food Hygiene in Eldoret, Kenya. International Journal of Current Research; 4(04):127-138.

\section{Author Note}

Correspondence: Ifeoluwapo O Asekun-Olarinmoye, Lecturer in Epidemiology, Department of Public Health, School of Public and Allied Health, College of Medicine, Babcock University, Ilishan-Remo, Ogun State, PMB 21244, Ikeja, Lagos, Nigeria; Email: ifeoluwapo.oyebola@gmail.com 